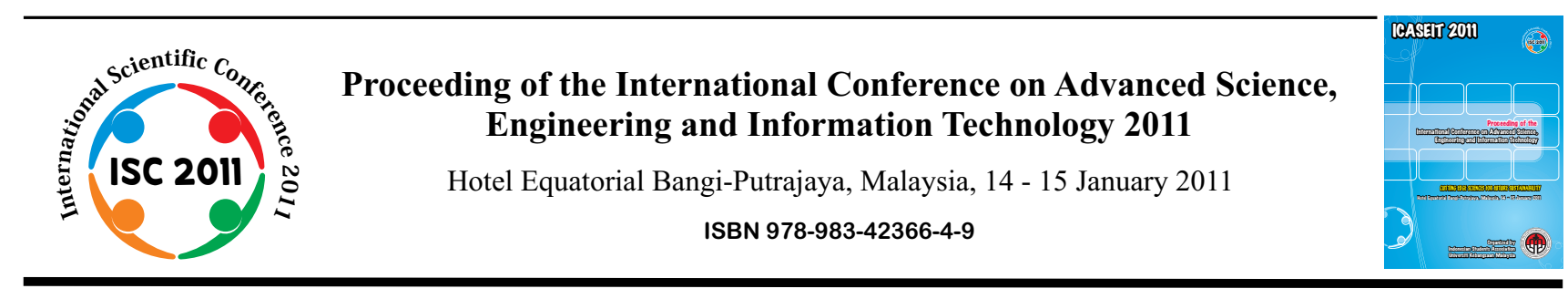

\title{
Modelling of 0.5HP Induction Motor using AC Analysis Solver for Rotor Copper Bar material
}

\author{
I.Daut, N.Gomesh, M.Ezanni, Y. Yanawati, S. Nor Shafiqin, Y.M.Irwan, M.Irwanto \\ Electrical Energy and Industrial Electronic Systems \\ School of Electrical Systems Engineering \\ Universiti Malaysia Perlis (UniMAP), MALAYSIA \\ E-mail: ismail.daut@unimap.edu.my, gomesh@unimap.edu.my
}

\begin{abstract}
In this paper a FEM model of a three phase 0.5HP squirrel-cage induction motor is modelled by using FEM software. The model is then used to analyze and investigate the performance of the induction machine using copper rotor bar compared to the conventional aluminium rotor bar material. Calculation using analytical tools could not calculate precisely the required parameters in order to obtain an optimal model to build a prototype model. That is why FEM software has been used to obtain the required data such as the torque vs. speed, torque vs. slip, power loss vs. speed and power loss vs. slip. This work gives some reviews of the advantages by substituting copper for aluminum in the rotor bar of squirrel cage induction motor as a main strategy toward reaching substantially higher efficiency.
\end{abstract}

Keywords - Induction Motor, FEM, Torque, Speed, Losses, Copper rotor

\section{INTRODUCTION}

Induction motors are widely used for various industrial applications. However, their design parameters are evaluated from the formulae based on the approximations to actual flux distribution in the machine cross section. In the past, approximate methods have sufficed. However, at the present time, there is a greater need to build more efficient machines and to utilize material more economically. In recent years, the finite element method has become a very popular and practical tool for computing magnetic fields in electrical apparatus [1].

Direct measurement of rotor quantities in induction motors has always been a difficult task. Rotor currents and inferred via analytical or numerical methods. Precise knowledge of the rotor variables can help to improve motor design related to its efficiency. In both design and diagnostics of induction machines the precise knowledge of the rotor quantities is a crucial issue, nevertheless information on rotor variables is typically only available by computation. In particular the Finite Element method (FEM) is used to compute the map of current and flux density distribution, while coupled circuits models or winding function approach are employed for the evaluation of stator and rotor currents [2]. The proposed calculation method is simple to use and the results required from the finite element (FE) analysis can be directly extracted from the postprocessor, i.e., there is no need to make any additional calculations from the magnetic vector potential solution.

There has been, in recent years, an effort to make cast copper rotors for industrial use induction motors. The objective is to make motors more efficient because of the higher conductivity of copper. In addition, the reduced losses in such motors may lead to better design flexibility and therefore motors that are more compact [3].

The electrical conductivity of copper is nearly $60 \%$ higher than that of aluminum; one would expect the $I^{2} R$ losses in the rotor to be substantially lower if copper were substituted for aluminum as the conductive material of the squirrel cage structure. Motor modeling by several manufacturers has shown that motors with copper-containing rotors would have overall loss reductions of 15 to $20 \%$ [4]. The use of copper as the conductor of induction motor rotors would typically lead to improvements in efficiency, relative to motors using aluminum.

General concern for improved device efficiency is encouraged in some countries and less so in others. Use of a 
heavier more expensive material is not an intuitive way forward for many motor manufacturers especially when low first cost was the primary concern of an entrenched customer base. It remained to be shown and more generally appreciated that the copper rotor could in fact reduce both motor weight and cost [5].

\section{Modelling Of InduCtion Motor USING F.E.M SOFTWARE}

Figure 1 shows the modelled $0.5 \mathrm{HP}$ Induction motor by using FEM software. Figure 1 shows the 2 dimensional (2D) view of the designed induction motor with respect to stator $\&$ stator bars, rotor \& rotor bars and air gap from the FEM software.

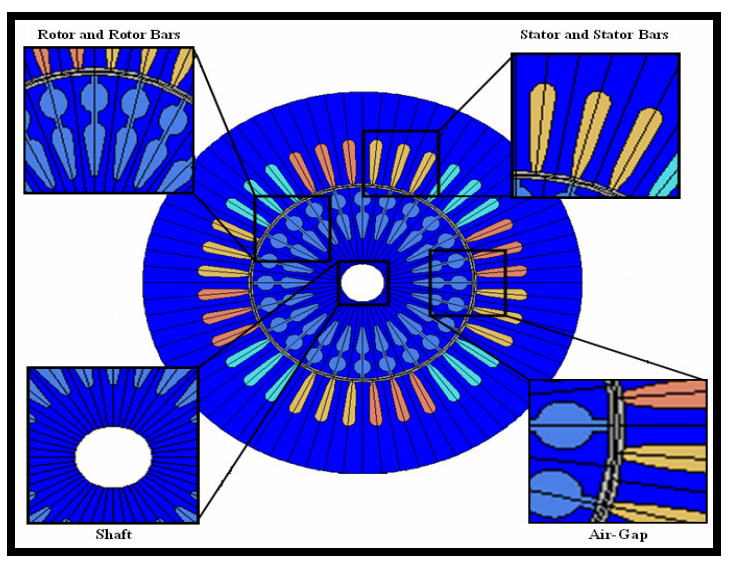

Figure 1: Modelling of 0.5HP Induction Motor

Table 1 shows the parameter of the $0.5 \mathrm{HP}$ induction motor based on laboratory experiment procedures used for the input in FEM software.

TABLE 1: SPECIFICATIONS FOR MODELLING OF 0.5HP INDUCTION MOTOR

\begin{tabular}{|l|l|l|}
\hline Description & Copper & Unit \\
\hline Phase voltage & 340 & $\mathrm{~V}($ peak $)$ \\
\hline Rated horsepower & 0.5 & $\mathrm{Hp}$ \\
\hline Rated output power & 0.37 & $\mathrm{~kW}$ \\
\hline Frequency & 50 & $\mathrm{~Hz}$ \\
\hline No of phases & 3 & - \\
\hline No. of poles & 4 & - \\
\hline Stator slots & 36 & - \\
\hline Rotor slots & 24 & - \\
\hline Synchronous Speed & 1500 & $\mathrm{rpm}$ \\
\hline Rotor Speed & 1425 & $\mathrm{rpm}$ \\
\hline Slip & 5 & $\%$ \\
\hline Conductivity & $5.8 \mathrm{E}-07$ & $\mathrm{~S} / \mathrm{m}$ \\
\hline
\end{tabular}

The FEM induction motors are designed to have 36 stator and 24 rotor slots design; the FEM uses steady-state AC analysis solver for copper rotor bar design. Based on the simulation, results from the copper materials are analysed. Copper conductivity is set to $5.8 \mathrm{E}-07$.

The BH curve used for the Aluminium and Copper rotor slot of the $0.5 \mathrm{hp}$ induction motor modelling has shown as Figure 2. The BH curve has been taken from FEM software which shows 1.8 Tesla and given below.

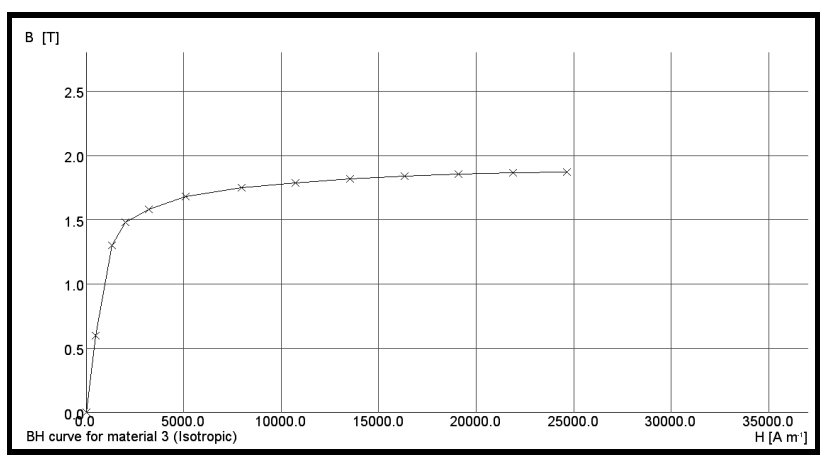

Figure 2: $\mathrm{BH}$ curve of the Copper material assigned for the $0.5 \mathrm{HP}$ induction Motor.

\section{STEAdy State AC ANALysis}

The result of steady state AC analysis for aluminum rotor bars and copper rotor bars is shown in Table 2. Based on the result, several graphs are plotted such as the torque vs. speed, torque vs. slip, power loss vs. speed and power loss vs. slip.

TABLE II: DATA FROM STEADy STATE AC ANALYSIS.

\begin{tabular}{|c|c|c|c|c|c|c|}
\cline { 5 - 8 } \multicolumn{2}{c}{} & \multicolumn{2}{c|}{ Aluminium } & \multicolumn{2}{c|}{ Copper } \\
\hline Speed (17m) & Freq (Hz) & Slip & Torque(N-m) & Power Loss (W) & Torque(N-m) & Power Loss (M) \\
\hline 1500 & 5.00 E-07 & $1.00 E-08$ & 8.33 E-03 & 2.19 E-13 & 8.33 E-03 & $3.62 E-13$ \\
\hline 1425 & 2.5 & 0.05 & 1.50 & 5.45 & 2.254 & 7.72 \\
\hline 1350 & 5.0 & 0.10 & 2.84 & 19.54 & 4.008 & 28.08 \\
\hline 1275 & 7.5 & 0.15 & 3.94 & 40.91 & 4.813 & 51.40 \\
\hline 1200 & 10.0 & 0.20 & 4.65 & 65.33 & 4.556 & 64.20 \\
\hline 1125 & 12.5 & 0.25 & 4.82 & 86.07 & 4.026 & 70.54 \\
\hline 1050 & 15.0 & 0.30 & 4.60 & 97.50 & 3.576 & 74.12 \\
\hline 975 & 17.5 & 0.35 & 4.26 & 104.47 & 3.217 & 79.26 \\
\hline 900 & 20.0 & 0.40 & 3.93 & 109.88 & 2.928 & 83.63 \\
\hline 825 & 22.5 & 0.45 & 3.64 & 114.56 & 2.694 & 86.89 \\
\hline 750 & 25.0 & 0.50 & 3.39 & 118.80 & 2.501 & 90.30 \\
\hline 675 & 27.5 & 0.55 & 3.17 & 122.77 & 2.342 & 93.93 \\
\hline 600 & 30.0 & 0.60 & 2.98 & 124.73 & 2.207 & 97.16 \\
\hline 525 & 32.5 & 0.65 & 2.82 & 131.28 & 2.094 & 101.55 \\
\hline 450 & 35.0 & 0.70 & 2.67 & 133.92 & 1.997 & 105.29 \\
\hline 375 & 37.5 & 0.75 & 2.55 & 136.70 & 1.913 & 110.55 \\
\hline 300 & 40.0 & 0.80 & 2.43 & 142.34 & 1.840 & 113.28 \\
\hline 225 & 42.5 & 0.85 & 2.33 & 144.93 & 1.776 & 117.98 \\
\hline 150 & 45.0 & 0.90 & 2.25 & 147.63 & 1.720 & 123.34 \\
\hline 75 & 47.5 & 0.95 & 2.17 & 153.42 & 1.671 & 126.769 \\
\hline 0 & 50.0 & 1.00 & 2.09 & 157.23 & 1.626 & 130.44 \\
\hline & & & & & & \\
\hline
\end{tabular}

Based on the Table 2 it is shown that as the rotor speed reaches $1425 \mathrm{rpm}$ the power loss for copper is higher $(7.72 \mathrm{~W})$ than in the aluminium $(5.45 \mathrm{~W})$. This is because copper has higher conductivity than aluminium and the heat generated by the copper material is much higher than aluminium at that rpm. The torque developed by a 
conventional 3-phase motor depends on its speed but the relation between the two cannot be represented by simple equation. It is easier to show the relationship in the form of a curve. In Figure 3 the starting torque (speed $=0$ ) of aluminium is at $2.09 \mathrm{~N}-\mathrm{m}$ and as for copper it is $1.63 \mathrm{~N}-\mathrm{m}$.

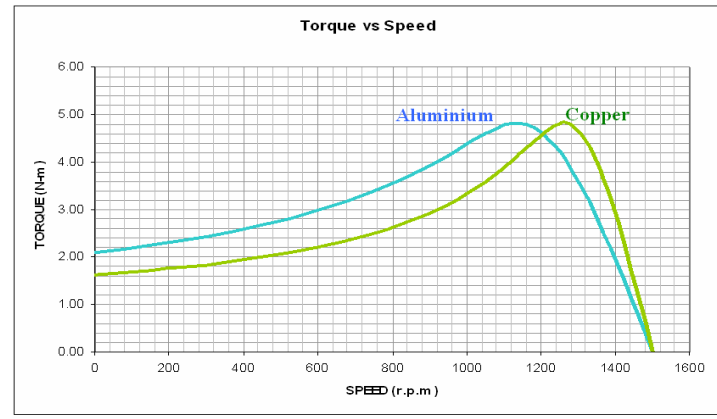

Figure 3: Torque vs. Speed of Aluminum \& Copper Rotor bar.

The maximum torque (breakdown torque) is $4.8 \mathrm{~N}-\mathrm{m}$ for both the materials. At full load the motor runs at the speed of $\mathrm{N}$. When the mechanical load increases, motor speed decreases until the motor torque again becomes equal to the load torque. As long as two of torques is in balance state, the motor will run at constant (but lower) speed. However, if the load torque exceeds $4.8 \mathrm{~N}-\mathrm{m}$ the motor will suddenly stop.

According to Figure 3, it shows that the copper rotor bar torque breaks down faster than the aluminum rotor bars. It shows that copper rotor bar is better than aluminium rotor bar because at fast breakdown speed, the heat generated from the motor is less compared to aluminium and the heat loss which is core loss can be reduced and this also can cause motor damage at minimum level.

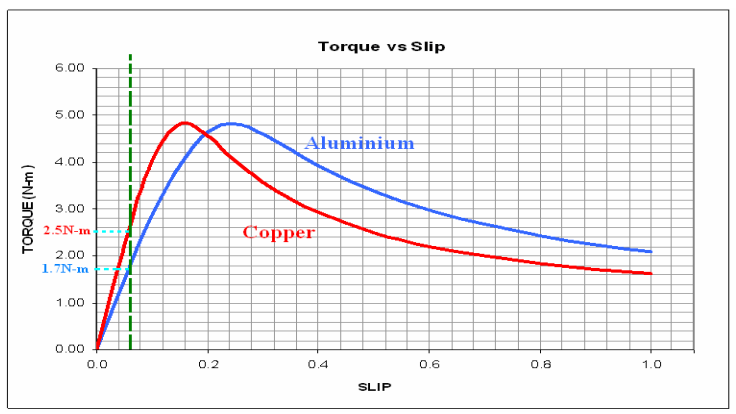

Figure 4: Torque vs. Slip comparison of Aluminum \& Copper Rotor bar.

For a given value of slip, torque is proportional to the square of voltage. The torque-slip characteristic at fixed (rated) is plotted in Figure 6.It is clear that when $\mathrm{s}=0, \mathrm{~T}=0$ hence the curve starts from point 0 .At normal speed, close to synchronism the term $\left(s X_{2}\right)$ is small and hence negligible with respect to $\left(R_{2}\right)$ shown in equation 1 .

$$
\therefore T \propto \frac{s}{R_{2}}
$$

Or

$$
T \propto s \text { if } R_{2} \text { is constant }
$$

So, for low values of slip, the torque/slip curve is approximately a straight line. As slip increases (for increasing load on the motor), the torque also increases and becomes maximum when $s=R_{2} / X_{2}$. This torque is known as pull-out or breakdown torque. As the slip further increases (i.e. motor speed falls) with further increase in motor load, then $R_{2}$ becomes negligible as compared to $s X_{2}$.According to Figure 4 if the motor slip of 0.05 is drawn a vertical line, the copper rotor bars torque will be higher than aluminum rotor bars torque. The copper rotor bars is leading maximum torque than the aluminum rotor bars, the maximum torque for copper rotor bars at 0.05 slip is $2.5 \mathrm{~N}-\mathrm{m}$ and for aluminium is $1.7 \mathrm{~N}-\mathrm{m}$. Even though at slip of 0.05 the aluminium motor torque is lesser than copper, but during breakdown torque the aluminium torque decreases slowly but reaches a torque level higher than copper.

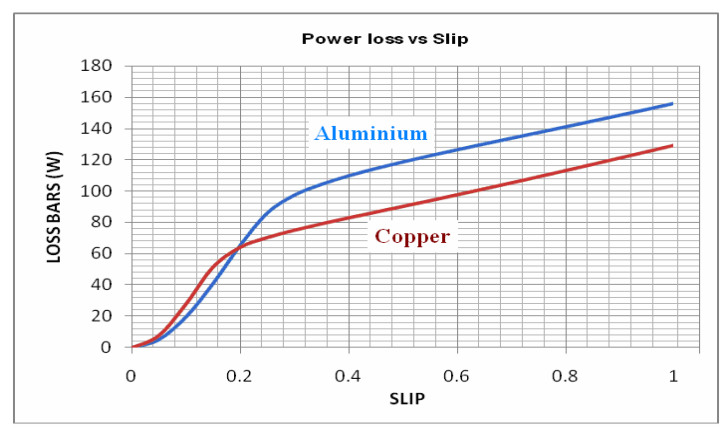

Figure 5: Power Loss vs. Slip of Aluminum \& Copper Rotor bar.

Figure 5 shows the power loss versus slip base on aluminum and copper rotor bars. At slip equals to 0 , the induction motor is at no load condition in which the rotor speed is almost same as the synchronous speed. When the motor is under load the slip is 0.05 based on the load test done in the experimental level. When motor is at 0.05 slip the power loss of the aluminium is $5.45 \mathrm{~W}$ and for copper is $7.72 \mathrm{~W}$ but even though the power loss of copper losses are more than the aluminium at that slip level, after both material losses is equal to each other at $0.2 \mathrm{slip}$ the aluminium losses surprisingly increase dramatically and the copper losses increase steadily but at nearly linear position. This shows that copper material is better than aluminium in terms of losses measurement.

Figure 6 shows the power loss vs. speed for aluminum and copper rotor bars. At starting condition, when speed is 0 r.p.m, power loss of copper rotor bars is $130.44 \mathrm{~W}$ and it is lower compare to aluminum rotor bars that is $157.23 \mathrm{~W}$. 


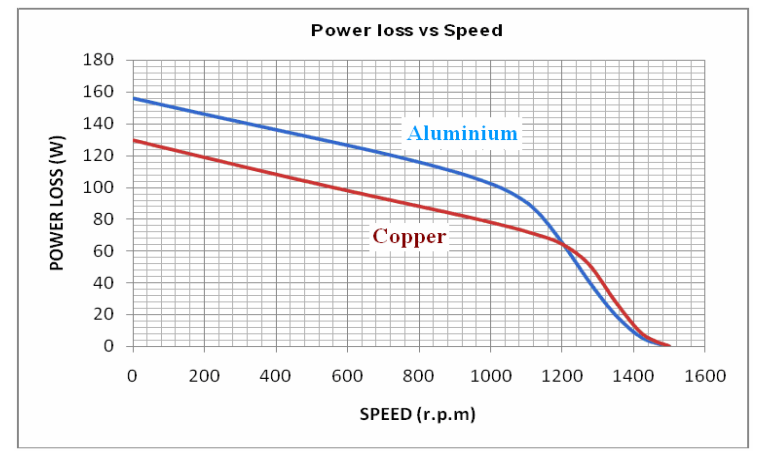

Figure 6: Power Loss vs. Speed (r.p.m) of Aluminum \& Copper Rotor bar.

This loss is dissipated in the form of heat as the motor is in block rotor condition. The loss in both of the material is proportionally decreasing with speed. When the speed is equal to 1200 r.p.m both of the material have equal losses. After that intersection, both materials rotor bar loss decreases until the speed is equal to synchronous speed. At the speed of 1000 r.p.m the aluminium rotor bars decreases slowly as the speed increases, but the copper rotor bars decreases linearly faster at 1200 r.p.m until reaches synchronous speed at no load condition. From this observation, the losses in induction motor are inverse proportional with speed so when the speed increases to synchronous speed (1500 rpm), the losses decreases. Based on the full load test in the experimental setup, the motor reaches the speed of 1425.3 r.p.m. As the speed is plotted in the figure above, $5.45 \mathrm{~W}$ for aluminium and $7.72 \mathrm{~W}$ for copper material is obtain

\section{CONCLUSION}

The topic addressed here is the torque, speed and slip as well as power loss, speed and slip characteristic comparison for aluminium and copper rotor bars. Through the use of higher conductivity copper and better steel, the efficiency of induction motors can be improved. To maintain satisfactory performance, including starting torque and current, motor design techniques have been developed, including shaping of rotor bars, stator slots design an so on. Based on the simulation of the FEM software it shows that copper rotor bar has fast breakdown speed, lower losses measurement and better linearity of losses along with slip compare to aluminium rotor bars.

\section{ACKNOWLEDGMENT}

The authors wish to thank School of Electrical Systems Engineering, Universiti Malaysia Perlis (UniMAP) for the technical and financial support.

\section{REFERENCES}

[1] S.C. Tandon, Finite Element Analysis of Induction Machines, IEEE Transactions on Magnetics, Vol. Mag- 18, No. 6, November 1982.

[2] O. Bottauscio, et al, From the Ideal to the Real Induction Machine: Modeling Approach and Experimental Validation, Journal of Magnetism and Magnetic Materials 320 (2008) e901-e906.

[3] James L. Kirtley Jr., Designing Squirrel Cage Rotor Slots with High Conductivity, Massachusetts Institute of Technology Cambridge, Massachusetts, 02139, USA.

[4] C. Stark, et al, Copper in the Rotor for Lighter, Longer Lasting Motors, ASNE San Diego Section Fleet Maintenance Symposium 2005.

[5] Dale T. Peters, Edwin F. Brush, Jr., James L. Kirtley, Jr., Die-Cast Copper Rotors as Strategy for Improving Induction Motor Efficiency,IEEE Xplore. 